\title{
Few European Adults are Living a Healthy Lifestyle
}

\author{
Adilson Marques, $\mathbf{P h D}^{1,2,3}{ }^{\mathbb{D}}$, Miguel Peralta, MS', João Martins, $\mathbf{P h D}^{4}$, \\ Vânia Loureiro, $\mathbf{P h D}^{5}$, Paola Cortés Almanzar, $\mathbf{M S}^{6}$, and \\ Margarida Gaspar de Matos, PhD $^{3,7}$
}

\author{
Abstract \\ Purpose: This study aimed to measure healthy lifestyle for European adults. \\ Design: Cross-sectional study. \\ Settings: In 20 European countries. \\ Participants: A total of 34993 (16 749 men, 18244 women) European adults.
}

Measures: Data were from the 2014 European Social Survey $(n=34993)$ on 4 modifiable behaviors (physical activity, fruit and vegetable consumption, not drinking alcohol to excess, and not smoking) as well as sleep quality.

Analysis: Behaviors were combined and formed a healthy lifestyle measure. Binary logistic regression was done to determine associations of healthy lifestyle and sociodemographic characteristics.

Results: Only $5.8 \%$ of the adults reported a healthy lifestyle. The prevalence of having a healthy lifestyle varied among European countries. The lowest rates were in Hungary (I.3\%) and Czech Republic (1.9\%). The highest rates were in United Kingdom (8.6\%) and Finland (9.2\%). Those who presented a higher likelihood of having a healthy lifestyle were middle age (odds ratio [OR] $=1.20)$, older people $(O R=1.34)$, having higher household income $(O R=I .33)$, being a student $(O R=I .38)$, and retired $(O R=I .31)$. Those less likely to have a healthy lifestyle were lived without a partner $(O R=0.82)$, unemployed $(O R=0.73)$, and lived in rural areas $(\mathrm{OR}=0.86)$.

Conclusions: Few European adults were practicing 5 healthy behaviors. This should be a message for governments and be considered in the establishment of preventive public policies in the areas of health and health education.

\section{Keywords}

getting cooperized, physical activity, vegetables consumption, drink alcohol, smoking, sleep quality, smoking, social and physical health, culture change

\section{Introduction}

It is recognized that behaviors are the key determinants of health and that positive changes can reduce rates of chronic disease and improve health outcomes. ${ }^{1-3}$ Some of the most important behaviors associated with health are physical activity, healthy diet, moderate alcohol consumption, and not smoking. ${ }^{4-6}$ Besides these behaviors, sleeping is now considered an important health behavior related to health status. ${ }^{7,8}$

A healthy lifestyle should be a combination of behaviors. In the literature, several attempts to measure lifestyle can be found, including at least 3 of the behaviors considered as the most important ones. ${ }^{9}$ Research has shown that a healthy lifestyle is associated with better health outcomes and lower mortality rates. ${ }^{10-13}$

Using measures of physical activity, diet, alcohol consumption, and smoking, a composite measure of healthy
' Centro Interdisciplinar do Estudo da Performance Humana, Faculdade de Motricidade Humana, Universidade de Lisboa, Lisboa, Portugal

${ }^{2}$ Centro de Investigação em Saúde Pública, Escola Nacional de Saúde Pública, Universidade Nova de Lisboa, Lisboa, Portugal

${ }^{3}$ Instituto de Saúde Ambiental, Faculdade de Medicina, Universidade de Lisboa, Lisboa, Portugal

${ }^{4}$ Laboratório de Pedagogia, Faculdade de Motricidade Humana e UIDEF, Instituto de Educação, Universidade de Lisboa, Lisboa, Portugal

${ }^{5}$ Escola Superior de Educação, Instituto Politécnico de Beja, Beja, Portugal

${ }^{6}$ Centro Universitario de la Costa, Universidad de Guadalajara, Puerto Vallarta, México

${ }^{7}$ Faculdade de Motricidade Humana, Universidade de Lisboa, Lisboa, Portugal

\section{Corresponding Author:}

Adilson Marques, Faculdade de Motricidade Humana, Universidade de Lisboa, Estrada da Costa, I499-002 Cruz Quebrada, Portugal.

Email: amarques@fmh.ulisboa.pt 
lifestyle was created, and it found that in the United States only $3 \%$ of the adults had a healthy lifestyle. ${ }^{14}$ Recently, based on the Healthy People 2020 agenda, a new composite measure for the US population was created, including sleep. ${ }^{15}$ In that study, $7.7 \%$ of the adults reported a healthy lifestyle. However, in spite of these studies, there is not much information about the prevalence of healthy lifestyles in European countries. Thus, it is important to have more knowledge in this area which could help to improve public health guidelines. Therefore, the purpose of this study was to analyze the healthy lifestyle for European adults, using data from the European Social Survey 2014. The association between lifestyle and sociodemographic characteristics of the population was also reported.

\section{Methods}

\section{Data and Participants}

Data were retrieved from the European Social Survey 2014 database. The European Social Survey is a study that has been conducted every 2 years since 2002 to measure the attitudes, beliefs, and behaviors of European adults. This survey uses representative samples among countries, from residents aged 15 years and over, excluding the homeless and institutionalized people. Participants were 40185 people from 20 European countries (Austria, Belgium, Czech Republic, Denmark, Estonia, Finland, France, Germany, Hungary, Ireland, Lithuania, Netherlands, Norway, Poland, Portugal, Slovenia, Spain, Sweden, Switzerland, and United Kingdom) and Israel. Participants were sampled by postal code, address files, social security registry data, population registers, and/or telephone books. The information was collected in each country, using a questionnaire filled in through an hour-long, face-to-face interview. The questionnaire was translated, by language experts, into the language spoken in each of the participating countries. More details about the European Social Survey are available elsewhere. ${ }^{16}$ The study protocol subscribes to the Declaration on Professional Ethics of the International Statistical Institute.

For the present study, participants under 18 years of age were excluded $(n=1215)$ because the focus was on the adult population. Respondents without information in more than 2 sociodemographic variables, and without information regarding physical activity, eating habits, sleep quality, alcohol drinking, and smoking were also excluded $(\mathrm{n}=1201)$. Since Israel is not a European country, its participants were excluded $(\mathrm{n}=$ 2136). These restrictions resulted in a final sample of 34993 participants (Austria $=1714$, Belgium $=1632$, Czech Republic $=1981$, Denmark $=1418$, Estonia $=1890$, Finland $=1960$, France $=1750$, Germany $=2831$, Hungary $=1596$, Ireland $=$ 2251 , Lithuania $=1877$, Netherlands $=1800$, Norway $=1376$, Poland $=1471$, Portugal $=1160$, Slovenia $=1141$, Spain $=$ 1843 , Sweden $=1697$, Switzerland $=1454$, and United Kingdom $=2152$ ).

\section{Measures}

Healthy lifestyle behaviors. The 5 behaviors used for the creation of the healthy lifestyle measure included physical activity, fruit and vegetable consumption, sleep quality, alcohol drinking, and smoking. These behaviors are all recognized as important behaviors associated with health. ${ }^{4-6,8}$

Physical activity was assessed with a single item asking, "On how many of the last 7 days did you walk quickly, do sports, or other physical activity for 30 minutes or longer?" Although physical activity was assessed by a single question, there is evidence that this is an acceptable way to assess physical activity ${ }^{17}$; this approach was used previously with the European Social Survey data. ${ }^{18,19}$ Participants were classified as having attained the recommended level of physical activity ( $\geq 30$ minutes of at least moderate physical activity on $\geq 5$ occasions per week) or not having attained the physical activity recommended levels ( $<30$ minutes of at least moderate physical activity on $\geq 5$ occasions per week), according to the European Physical Activity guidelines. ${ }^{20}$

Fruit and vegetable consumption was addressed through the questions, "How often do you eat fruit, excluding drinking juice?" and "How often you eat vegetables or salad, excluding potatoes?" Responses to these 2 questions were combined to assess the total fruit and vegetable daily consumption. Several dietary guidelines advise the consumption of $\geq 5$ portions of fruit and vegetables per day. ${ }^{21}$ However, in Europe, the definition of fruits and vegetables, and its recommendations, varies between countries. ${ }^{22}$ Therefore, to have a cutoff point that was suitable for all countries, the consumption of $\geq 4$ portions of fruits or vegetables (or fruit and vegetables combined) a day was considered appropriate.

The European Social Survey data does not have information of sleep duration. It does provide information regarding sleep quality. As a proxy of the sleep behavior, the information provided in the question was used: "For how much of the time, during the past week, was your sleep was restless?" Response options were: "none or almost none of the time," "some of the time," "most of the time," and "all or almost all of the time." Healthy sleep behavior was considered if respondents answered that sleep was restless none or almost none of the time. The other response options were considered unsatisfactory sleep quality.

The amount of alcohol consumed was measured in grams, derived by adding the reporting of all beverages consumed the last time the respondent drank alcohol on a weekday and the last time the respondent drank alcohol on a weekend day, respectively. Alcohol consumption guidelines vary between countries in Europe. ${ }^{23}$ For this study, the guidelines from the Department of Health ${ }^{24}$ were adopted. This more restrictive recommendation was used because there is evidence that alcohol consumption, even at moderate levels, is associated with adverse brain outcomes. ${ }^{25}$ Light drinking was defined as between 1 and $<7$ units/week and moderate drinking was 7 to $<14$ units/week for women and 7 to $<21$ units/week for men. 
Not drinking excessively was defined as $\leq 14$ units/week (112 g) for women and $\leq 21$ units/week (168 g) for men.

Participants were asked about their smoking behavior. Response options ranged from, "I have never smoked" to "I smoke every day". Because there is no threshold of safety for smoking cigarettes, responses were recoded into current smoker (regularly or sometimes), and not smoking.

Healthy lifestyle composite score. The composite score of healthy lifestyle was created using the combination of the 5 healthy behaviors described above. Participants scored 1 point for achieving each of the following lifestyle categories: (1) physical activity $\geq 5$ times/week, (2) consumption of $\geq 4$ portions of fruits and vegetables a day, (3) not having a restless sleep, (4) not drinking excessively, and (5) not smoking. Thus, the healthy lifestyle score ranged from 0 to 5 , with only a score of 5 representing a healthy lifestyle. To ensure that the composite score of healthy lifestyle was related to a better health, it was analyzed its relationship with self-rated health, life satisfaction, and the number of chronic diseases. It was clear that people with a healthy lifestyle had better health perception, reported better life satisfaction, and also less chronic diseases.

Other variables. Participants reported sex, age, and years of fulltime education (recorded as low, middle, and high, according to the International Standard Classification of Education). ${ }^{26}$ Respondents were asked to describe whether they live with or without a husband/wife/partner and the legal situation. Response options were dichotomized into live with, or without, a partner. Household income was determined based on decile. Using this data, 1st to 3rd decile, 4th to 7th decile, and 8th to 10th were organized to create 3 groups. Participants were asked to report their occupation. To determine the living place, those who indicated that they lived in a big city, the suburbs, or the outskirts of a big city were grouped into a new category named "urban areas"; those who responded that they lived in the countryside, in a village, or in a house in the countryside were grouped into a category called "rural areas."

\section{Data Analysis}

Descriptive statistics were calculated (means, standard deviation, and percentages) for the entire sample and were stratified by sex. Point estimates and $95 \%$ confidence intervals (CIs) were reported for the prevalence for each of the healthy lifestyle behaviors, for the number of behaviors reported, and for the mean number of behaviors reported. Chi-square and Student $t$ test were used to compare men and women according to sociodemographic characteristics and healthy lifestyle behavior. Binary logistic regression was done to determine associations of healthy lifestyle and sociodemographic characteristics. Statistical analysis was performed using SPSS version 24 . The significance level was set at $P<.05$.
Table I. Participants' Sociodemographic Characteristics.

\begin{tabular}{|c|c|c|c|c|}
\hline & $\begin{array}{c}\text { Total, } \\
\mathrm{N}=34993\end{array}$ & $\begin{array}{c}\text { Men, } \\
\mathrm{n}=16749\end{array}$ & $\begin{array}{c}\text { Women, } \\
\mathrm{n}=18244\end{array}$ & $P$ \\
\hline Age, years & & & & $<.001$ \\
\hline $18-39$ & 31.2 & 31.9 & 30.5 & \\
\hline $40-64$ & 43.8 & 44.0 & 43.7 & \\
\hline$\geq 65$ & 25.0 & 24.1 & 25.8 & \\
\hline Education level & & & & $<.001$ \\
\hline Low & 26.2 & 20.6 & 30.8 & \\
\hline Middle & 51.6 & 57.1 & 46.0 & \\
\hline High & 22.4 & 22.0 & 22.3 & \\
\hline Marital status & & & & $<.001$ \\
\hline Live with partner & 60.6 & 63.5 & 58.1 & \\
\hline $\begin{array}{l}\text { Live without } \\
\text { partner }\end{array}$ & 39.4 & 36.5 & 41.9 & \\
\hline Household income & & & & $<.001$ \\
\hline $\begin{array}{l}\text { Low (Ist to 3rd } \\
\text { decile) }\end{array}$ & 30.8 & 26.6 & 34.5 & \\
\hline $\begin{array}{l}\text { Middle (4th to } 7 \text { th } \\
\text { decile) }\end{array}$ & 42.4 & 43.9 & 41.1 & \\
\hline $\begin{array}{l}\text { High (8th to 10th } \\
\text { decile) }\end{array}$ & 26.8 & 29.5 & 24.3 & \\
\hline Occupation & & & & $<.001$ \\
\hline Employed & 60.6 & 60.1 & 61.1 & \\
\hline Unemployed & 5.7 & 6.5 & 5.1 & \\
\hline Student & 6.3 & 6.4 & 6.0 & \\
\hline Retired & 27.4 & 27.0 & 27.8 & \\
\hline Living place & & & & .001 \\
\hline Urban area & 65.2 & 63.3 & 65.0 & \\
\hline Rural area & 34.8 & 36.7 & 35.0 & \\
\hline
\end{tabular}

\section{Results}

Table 1 presents the characteristics of the study sample. Prevalence rates for each of the healthy lifestyle behaviors are shown at the top of Table 2. The range of rates was from $21 \%$ for eating fruits and vegetables $\geq 4$ times/day, and $89.1 \%$ for not drinking excessively. Comparing sexes, men were more likely to engage in physical activity $\geq 5$ days/week than women $(34.5 \%$ vs $32 \%, P<.001)$ and were also more likely not to have restless sleep than women ( $87 \%$ vs $79.8 \%$, $P<.001)$. On the other hand, women were more likely to eat $\geq 4$ portions/day of fruits and vegetables $(25.7 \%$ vs $15.7 \%, P<.001)$, not drink excessively $(91.2 \%$ vs $86.8 \%$, $P<.001)$, and not smoke $(79.6 \%$ vs $71.3 \%, P<.001)$ than men. Only $5.8 \%$ (4.7\% men, $6.7 \%$ women) of the adults reported achieving all 5 healthy behaviors, while $42.3 \%$ ( $42.6 \%$ men, $42.1 \%$ women) reported at least 3 behaviors.

Figure 1 presents the prevalence of healthy lifestyle (achieving all 5 healthy behaviors) by countries. The lowest rates were in Hungary (1.3\%), Czech Republic (1.9\%), and Austria (2.8\%). The highest rates were in Spain (8.1\%), United Kingdom (8.6\%), and Finland (9.2\%). It was not possible to observe a pattern according to European geographic regions.

The relationship between having a healthy lifestyle and sociodemographic factors is presented in Table 3. For the 
Table 2. Behavior of a Composite Healthy Lifestyle Measure, for European Adults.

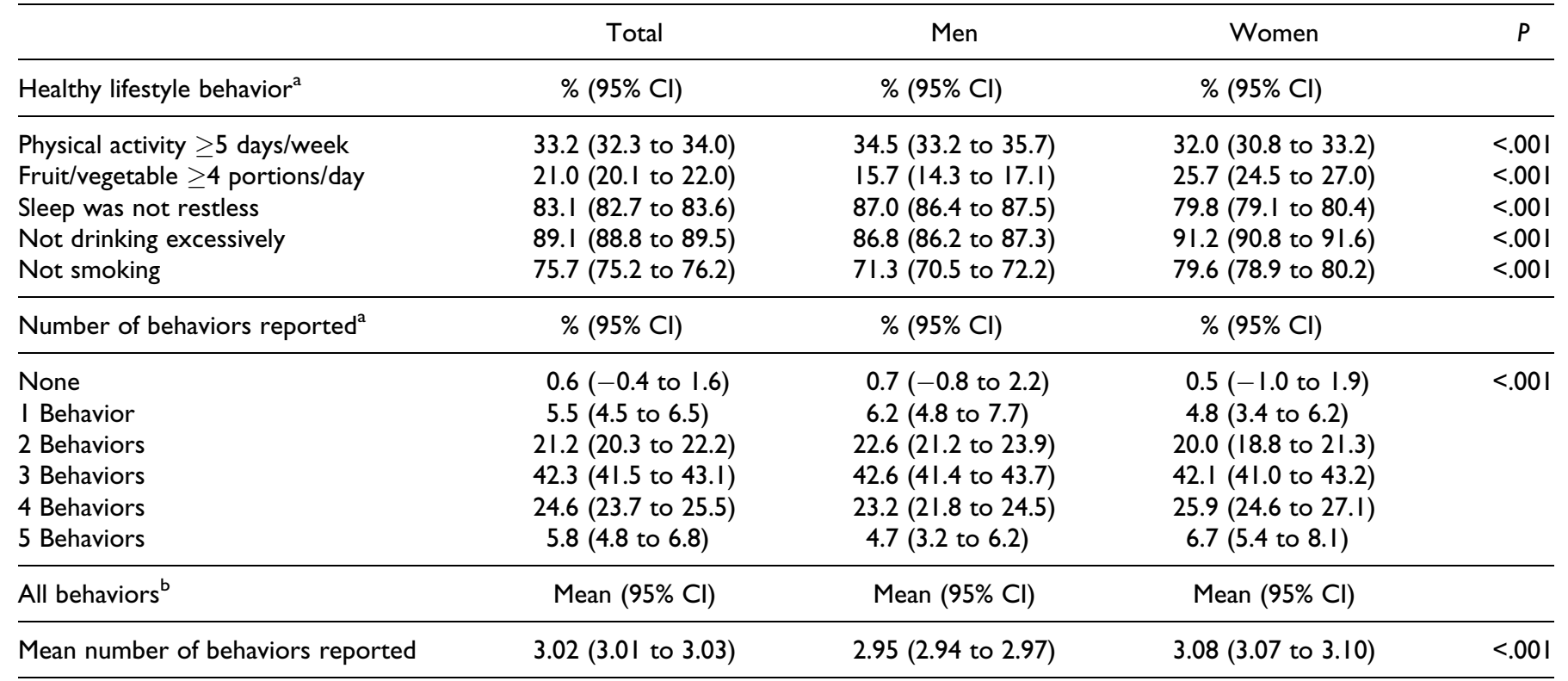

Abbreviation: $\mathrm{Cl}$, confidence interval.

${ }^{\text {a }}$ Differences between sexes were tested by Chi-square.

${ }^{\mathrm{b}}$ Differences between sexes were tested by Student $t$ test.

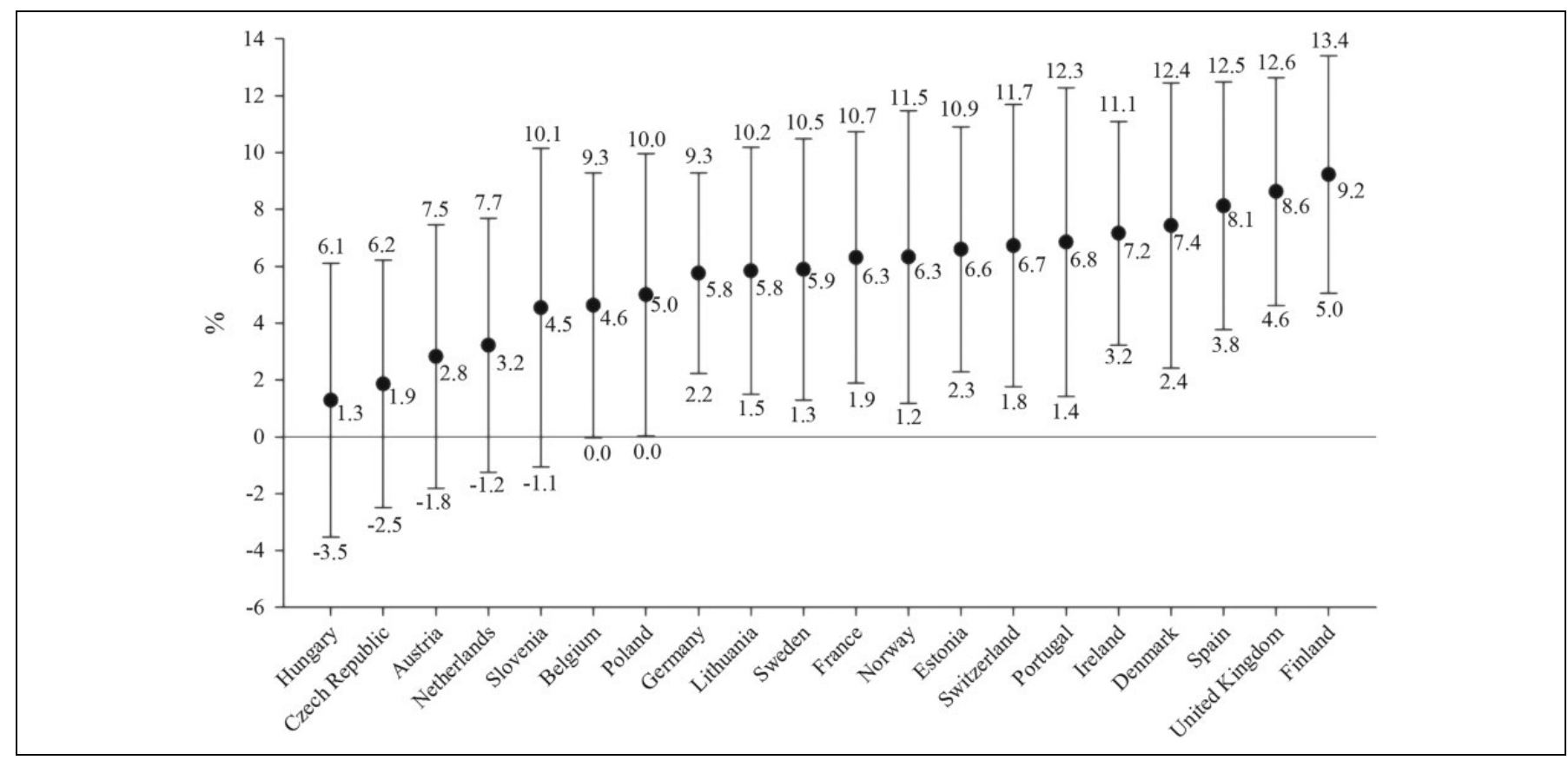

Figure I. Percentage, and $95 \%$ confidence interval, of the population with a healthy lifestyle (achieving all healthy behaviors) by European countries.

entire sample, middle age (odds ratio $[\mathrm{OR}]=1.20,1.04-1.38, P$ $<.05)$, older people (OR $=1.34,95 \%$ CI: $1.07-1.67, P<.001)$, those having higher household income $(\mathrm{OR}=1.33,95 \% \mathrm{CI}$ : $1.15-1.54)$, being a student $(\mathrm{OR}=1.38,95 \% \mathrm{CI}: 1.08-1.77)$, and retired $(\mathrm{OR}=1.31,95 \% \mathrm{CI}: 1.12-1.52, P<.001)$ presented a higher likelihood of having a healthy lifestyle. On the contrary, those who lived without a partner $(\mathrm{OR}=0.82,95 \%$ CI: 0.73 $0.93, P<.001$ ), unemployed (OR $=0.73,95 \%$ CI: $0.55-0.97, P$ $<.05)$, and lived in rural areas ( $\mathrm{OR}=0.86,95 \% \mathrm{CI}: 0.77-0.96$, $P<.01)$ were less likely to have a healthy lifestyle. For men, education level and living places were sociodemographic characteristics related to a healthy lifestyle but not in women. 
Table 3. Results of Multivariate Binary Logistic Regression for a Healthy Lifestyle as Outcome, for European Adults.

\begin{tabular}{|c|c|c|c|}
\hline & Total OR $(95 \% \mathrm{Cl})$ & Men OR $(95 \% \mathrm{Cl})$ & Women OR $(95 \% \mathrm{Cl})$ \\
\hline \multicolumn{4}{|l|}{ Age, years } \\
\hline $18-39$ & 1.00 (ref.) & 1.00 (ref.) & 1.00 (ref.) \\
\hline$\geq 65$ & $1.34(1.07-1.67)^{b}$ & $1.53(1.06-2.21)^{\mathrm{a}}$ & $1.24(0.94-1.64)$ \\
\hline \multicolumn{4}{|l|}{ Education level } \\
\hline Low & $\mathrm{I} .00$ (ref.) & 1.00 (ref.) & $\mathrm{I} .00$ (ref.) \\
\hline \multicolumn{4}{|l|}{ Marital status } \\
\hline Live with partner & $\mathrm{I} .00$ (ref.) & $\mathrm{I} .00$ (ref.) & $\mathrm{I} .00$ (ref.) \\
\hline Live without partner & $0.82(0.73-0.93)^{\mathrm{b}}$ & $0.75(0.6 \mathrm{I}-0.92)^{\mathrm{b}}$ & $0.84(0.72-0.98)^{\mathrm{a}}$ \\
\hline \multicolumn{4}{|l|}{ Household income } \\
\hline Low (Ist to 3rd decile) & $\mathrm{I} .00$ (ref.) & I.00 (ref.) & I.00 (ref.) \\
\hline Middle (4th to 7 th decile) & $1.12(0.98-1.29)$ & $1.14(0.91-1.42)$ & $1.18(1.00-1.40)$ \\
\hline Student & $1.39(1.08-1.79)^{\mathrm{a}}$ & $1.75(1.18-2.58)^{b}$ & $1.23(0.88-1.72)$ \\
\hline Retired & $1.36(1.13-1.64)^{b}$ & $1.36(0.99-1.85)$ & $1.38(1.10-1.74)^{a}$ \\
\hline \multicolumn{4}{|l|}{ Living place } \\
\hline Urban area & 1.00 (ref.) & 1.00 (ref.) & $\mathrm{I} .00$ (ref.) \\
\hline Rural area & $0.86(0.77-0.96)^{b}$ & $0.83(0.70-0.99)^{a}$ & $0.89(0.78-1.02)$ \\
\hline
\end{tabular}

Abbreviations: $\mathrm{OR}$, odds ratio; $\mathrm{Cl}$, confidence interval.

${ }^{\mathrm{a}} \mathrm{P}<.05$.

${ }^{\mathrm{b}} \mathrm{P}<.0 \mathrm{l}$.

${ }^{c} P<.001$

\section{Discussion}

This study aimed to measure healthy lifestyle for European adults. Despite the recognized importance of engaging in physical activity regularly, eating fruits and vegetables daily, sleeping well to rest, not drinking excessively, and not smoking, very few European adults have a healthy lifestyle as defined here. Physical activity and fruit and vegetable consumption seemed to be the behaviors that offer the best possibilities to improve the composite measure and have more people healthier. Differences among countries were observed. The relationship between the composite measure of healthy lifestyle and sociodemographic factors demonstrated that there are some social inequities. For example, people with high household income were more likely to have a healthy lifestyle, when compared to those from lower household income.

Results from this study were similar with an earlier study in the United States, which also found a low rate of people with a healthy lifestyle, although the measure was slightly different. ${ }^{15}$ The similar results between European and Unites States population indicate that people from these 2 regions have comparable lifestyles. The lower prevalence of healthy lifestyle in Europe and the United States might be a function of the individual lifestyle characteristics and how the behaviors aggregate or cluster together. Among the healthy lifestyle behaviors, physical activity and fruit and vegetable consumption had the lowest prevalence. This is consistent with the high prevalence of physical inactivity ${ }^{27,28}$ and low consumption of fruits and vegetables among European adults. ${ }^{29}$ As a response, the World Health Organization and the European Union have implemented strategies that aim to enhance the levels of physical activity and fruit and vegetable consumption in Europe, in order to reduce the prevalence and incidence of chronic disease and premature death. ${ }^{3,29}$

A healthy lifestyle or a combination of at least 4 behaviors (eg, engaging in physical activity regularly, having a healthy diet, moderate alcohol intake, and never smoking) is related to reduction in morbidity, ${ }^{11,12}$ mortality, ${ }^{9}$ and having a longer life with good health. ${ }^{10}$ Thus, considering that lifestyle behaviors, either individually or combined into a composite score, are associated with health outcomes, ${ }^{10-12}$ European adults seem to be at risk of having chronic diseases, because $<6 \%$ are reported to have reached all 5 healthy behaviors.

Several studies still analyze individual health behaviours. ${ }^{9}$ However, looking at the health behaviors individually, one could say that, for example, the majority of the population does not drink excessively or does not smoke. When assessing healthy lifestyle based on a single behavior, it seems that a high proportion of the adult population has a healthy lifestyle. On the other hand, as previously acknowledged, ${ }^{15}$ a measure of healthy lifestyle offers a new public health perspective, usually using recognized health behaviours ${ }^{30}$ and provides new insight 
into the population's health status. When using a composite measure of healthy lifestyle, it is highlighted that more than $90 \%$ of the European adult population should be targeted for improving their health. Therefore, a more holistic approach seems to be more accurate to determine the lifestyle and to point out new directions for improving. For instance, the lower prevalence of engaging in regular physical activity and fruit and vegetable consumption underlines the need to work more in these areas. It means that investments in promoting these behaviors might increase the number of people with a healthy lifestyle. These results demonstrate the usefulness of the healthy lifestyle composite measurement, mainly because research has made clear that having 4 or more healthy behaviors decreased the risk of mortality. ${ }^{9}$ For that reason, a refined version of a healthy lifestyle composite score, using standardized variables that can be used in different countries and regions, would be an advantage for international comparative investigations. This would be important for policy makers, because they would be able to compare results among countries and regions, encouraging international collaboration in initiatives to face mutual challenges associated with unhealthy lifestyles.

People, men and women, with higher household income are more likely to have a healthy lifestyle compared to those with lower household income. Likewise, more educated men, and people who live in urban areas, have a better likelihood of having a healthy lifestyle. Such results show that there are social inequities toward having a healthy lifestyle. The World Health Organization has been addressing several messages to reduce social inequities in health promotion, mainly for the prevention and control of chronic diseases. ${ }^{3,31}$ It is recommended that policy makers need to engage in planning actions to promote healthy lifestyles and reduce social inequities. ${ }^{32}$ For this purpose, interventions have to tackle the macro-environmental factors, the social and physical environment, the adverse health behaviors, and access to health-care services. ${ }^{3,31}$

There are several limitations in this study. All data were self-reported, and reliability and validity have not been studied for all measured healthy lifestyle behaviors. So far, there is no consensus regarding how to define a healthy lifestyle. In Europe, there are different guidelines for fruit and vegetable consumption, as well as guideline variations between countries, so it is difficult to define a cutoff point. ${ }^{22}$ There is also no consensus concerning the specific nutritional components that constitute a healthy diet. Similarly, the amount of alcohol defined as moderate consumption is not the same in all European countries. ${ }^{23}$ For these reasons, guidelines from the Department of Health were adopted, which are more conservative. ${ }^{24}$ A question to assess sleep duration was not included; thus, a proxy variable of sleep was used instead. Although this variable provided information on quality of sleep, there was no guarantee that participants had slept $\geq 7$ hour per night, as recommended. ${ }^{33}$ Furthermore, the crosssectional design of the study precludes making a causal inference for the relationship between healthy lifestyle and

\section{SO WHAT?}

\section{What is already known on this topic?}

Healthy lifestyle is combination of behaviors, and a healthy lifestyle is associated with better health outcomes and lower mortality rates.

\section{What does this article add?}

Although engaging in physical activity regularly, eating fruits and vegetables daily, sleeping well, not drinking excessively, and not smoking are well recognized as being related to health outcomes, less than $6 \%$ of European adults reported achieving all 5 healthy behaviors. Physical activity and fruit and vegetable consumption seemed to be the behaviors that offer the best possibilities to improve the healthy lifestyle of European people.

\section{What are the implication for health promotion practice or research}

A refined healthy lifestyle composite score, using the same variables in different countries and regions, would be an advantage for comparative investigations. An international healthy lifestyle composite score would help policymakers to compare results among countries and regions, encouraging international collaboration in initiatives to face mutual challenges associated with unhealthy lifestyles.

sociodemographic factors. Results need to be interpreted with the above issues in mind.

\section{Conclusions}

This study presents a new composite lifestyle measure for European people, comprised of engaging in physical activity regularly, eating fruits and vegetables daily, sleeping well, not drinking excessively, and not smoking. Although these 5 behaviors are well recognized as being related to health outcomes, $<6 \%$ of European adults reported all 5 healthy behaviors. From this study's results, it is clear that enhancing the levels of physical activity and fruit and vegetable consumption offers the greatest potential for improving the prevalence of European adults with a healthy lifestyle. This should be both a message for governments and a consideration in the establishment of preventive public policies in the areas of health and health education.

\section{Authors' Note}

Study conception and design: AM, MP, MGM; acquisition of data: AM, MGM; analysis and interpretation of data: JM, VL, PCA; 
drafting of manuscript: AM, MP; critical revision: AM, MP, JM, VL, PCA, MGM.

\section{Acknowledgments}

The authors thank Bruce Jones for revising the document.

\section{Declaration of Conflicting Interests}

The author(s) declared no potential conflicts of interest with respect to the research, authorship, and/or publication of this article.

\section{Funding}

The author(s) received no financial support for the research, authorship, and/or publication of this article.

\section{ORCID iD}

Adilson Marques (D) http://orcid.org/0000-0001-9850-7771

\section{References}

1. Centers for Disease Control and Prevention. The Power of Prevention. Chronic Disease the Public Health Challenge of the 21st Century. Atlanta, GA: Centers for Disease Control and Prevention; 2009.

2. European Chronic Disease Alliance. Optimising the Response to the Epidemic of Chronic Diseases. European Chronic Disease Alliance Input to the Reflection Process on Chronic Diseases. Brussels: European Chronic Disease Alliance; 2012.

3. World Health Organization. Global Action Plan for the Prevention and Control of Noncommunicable Diseases 2013-2020. Geneva, Switzerland: World Health Organization; 2013.

4. World Health Organization. Prevention and Control of Noncommunicable Diseases in the European Region: A Progress Report. Copenhagen, Denmark: World Health Organization; 2014.

5. Brownson RC, Remington PL, Wegner MV. Chronic Disease Epidemiology and Control. Washington, DC: American Public Health Association; 2010.

6. Rayner M, Wickramasinghe K, Williams J, McColl K, Mendis S. An Introduction to Prevention of Non-Communicable Diseases. Oxford, England: Oxford University Press; 2017.

7. Grandner MA, Hale L, Moore M, Patel NP. Mortality associated with short sleep duration: the evidence, the possible mechanisms, and the future. Sleep Med Rev. 2010;14(3):191-203.

8. Cable N, Chandola T, Aida J, Sekine M, Netuveli G. Can sleep disturbance influence changes in mental health status? Longitudinal research evidence from ageing studies in England and Japan. Sleep Med. 2017;30:216-221.

9. Loef M, Walach H. The combined effects of healthy lifestyle behaviors on all cause mortality: a systematic review and metaanalysis. Prev Med. 2012;55(3):163-170.

10. Fransen HP, May AM, Beulens JW, et al. Association between lifestyle factors and quality-adjusted life years in the EPIC-NL cohort. PLoS One. 2014;9(11):e111480.

11. Dhalwani NN, Zaccardi F, O'Donovan G, et al. Association between lifestyle factors and the incidence of multimorbidity in an older English population. J Gerontol A Biol Sci Med Sci. 2017; 72(4):528-534.
12. Fortin M, Haggerty J, Almirall J, Bouhali T, Sasseville M, Lemieux M. Lifestyle factors and multimorbidity: a cross sectional study. BMC Public Health. 2014;14:686.

13. Myint PK, Smith RD, Luben RN, et al. Lifestyle behaviours and quality-adjusted life years in middle and older age. Age Ageing. 2011;40(5):589-595.

14. Reeves MJ, Rafferty AP. Healthy lifestyle characteristics among adults in the United States, 2000. Arch Intern Med. 2005;165(8): 854-857.

15. Adams ML, Katz DL, Shenson D. A healthy lifestyle composite measure: significance and potential uses. Prev Med. 2016;84: 41-47.

16. Schnaudt C, Weinhardt M, Fitzgerald R, Liebig S. The European Social Survey: contents, design, and research potential. Schmollers Jahrbuch. 2014;134(4):487-506.

17. Wanner M, Probst-Hensch N, Kriemler S, Meier F, Bauman A, Martin BW. What physical activity surveillance needs: validity of a single-item questionnaire. Br J Sports Med. 2014;48(21): 1570-1576.

18. Marques A, Santos DA, Peralta M, Sardinha LB, Gonzalez Valeiro M. Regular physical activity eliminates the harmful association of television watching with multimorbidity. A crosssectional study from the European Social Survey. Prev Med. 2018;109:28-33.

19. Marques A, Santos T, Martins J, de Matos MG, Valeiro MG. The association between physical activity and chronic diseases in European adults. Eur J Sport Sci. 2018;18(1):140-149.

20. European Union. EU Physical Activity Guidelines Recommended Policy Actions in Support of Health-Enhancing Physical Activity. Brussels, Belgium: European Union; 2008.

21. Painter J, Rah JH, Lee YK. Comparison of international food guide pictorial representations. J Am Diet Assoc. 2002;102(4): 483-489.

22. Agudo A. Measuring Intake of Fruit and Vegetables. Kobe, Japan: World Health Organization; 2005.

23. Mongan D, Long J. Standard Drink Measures Throughout Europe; Peoples' Understanding of Standard Drinks and Their Use in Drinking Guidelines, Alcohol Surveys and Labelling. Dublin, Ireland: Health Research Board; 2015.

24. Department of Health. How to Keep Health Risks From Drinking Alcohol to a Low Level: Public Consultation on Proposed New Guidelines. Department of Health; 2016.

25. Topiwala A, Allan CL, Valkanova V, et al. Moderate alcohol consumption as risk factor for adverse brain outcomes and cognitive decline: longitudinal cohort study. BMJ. 2017;357: j2353.

26. United Nations Educational, Scientific and Cultural Organization. International Standard Classification of Education ISCED 2011. Montreal, Canada: United Nations Educational, Scientific and Cultural Organization; 2012.

27. European Commission. Special Eurobarometer 412. Sport and Physical Activity. Brussels, Belgium: European Commission, Directorate-General for Education and Culture and Co-ordinated by Directorate-General for Communication; 2014. 
28. Hansen BH, Kolle E, Dyrstad SM, Holme I, Anderssen SA. Accelerometer-determined physical activity in adults and older people. Med Sci Sports Exerc. 2012;44(2):266-272.

29. Organisation for Economic Co-operation and Development/ European Union. Health at a Glance: Europe 2016-State of Health in the EU Cycle. Paris, France: OECD Publishing; 2016.

30. Nolan T, Berwick DM. All-or-none measurement raises the bar on performance. JAMA. 2006;295(10):1168-1170.
31. Crombie I, Irvine L, Elliott L, Wallace H. Closing the Health Inequalities Gap: An International Perspective. Copenhagen, Denmark: WHO Regional Office for Europe; 2005.

32. Ridde V. Reducing social inequalities in health: public health, community health or health promotion? Promot Educ. 2007; 14(2):63-67, 111-114.

33. World Health Organization. WHO Technical Meeting on Sleep and Health. Copenhagen, Denmark: WHO Regional Office for Europe; 2004. 